\title{
Structural and compositional analyses of a strained AIGaN/GaN superlattice
}

\author{
M. Shiojiri ${ }^{\text {a) }}$ \\ Kyoto Institute of Technology, Kyoto 606-8585, Japan and Department of Anatomy, Kanazawa Medical \\ University, Ishikawa 920-0293, Japan \\ M. Čeh ${ }^{\text {b) }}$ and S. Šturm \\ Department of Nanostructured Materials, Jožef Stefan Institute, 1000 Ljubljana, Slovenia \\ C. C. Chuo and J. T. Hsu \\ Electronics and Optoelectronics Research Laboratories, Industrial Technology Research Institute, Hsinchu, \\ Taiwan 310, Republic of China \\ J. R. Yang \\ Institute of Materials Science and Engineering, National Taiwan University, Taipei, Taiwan 106, \\ Republic of China \\ H. Saijo ${ }^{\text {c) }}$ \\ Department of Electronics and Information Science, Kyoto Institute of Technology, Kyoto 606-8585, Japan
}

(Received 6 February 2006; accepted 5 May 2006; published online 12 July 2006)

\begin{abstract}
We investigated the nanostructure of $\mathrm{AlGaN} / \mathrm{GaN}$ strained-layer superlattice (SLS) cladding in a GaN-based violet laser diode (LD) using a scanning-transmission electron microscope (STEM). Metal-organic vapor-phase epitaxy was used to grow 200 pairs of $n$ - $\mathrm{Al}_{0.14} \mathrm{Ga}_{0.86} \mathrm{~N} / n$-GaN layers directly on the $n$-GaN: $\mathrm{Si}$ contact layer that was deposited on a (0001) sapphire substrate. The $\mathrm{Al}_{0.14} \mathrm{Ga}_{0.86} \mathrm{~N}$ and $\mathrm{GaN}$ layers were distinguished as dark and bright bands in the high-angle annular dark-field (HAADF) images taken in the $[\overline{12} \overline{1} 0]$ zone axis. The widths of the $\mathrm{Al}_{0.14} \mathrm{Ga}_{0.86} \mathrm{~N}$ and $\mathrm{GaN}$ layers were determined to be $2.24 \pm 0.09$ and $2.34 \pm 0.15 \mathrm{~nm}$, respectively. The lattice parameters of the $\mathrm{Al}_{0.14} \mathrm{Ga}_{0.86} \mathrm{~N}$ were measured to be $a=0.32 \pm 0.01 \mathrm{~nm}$ and $c=0.50 \pm 0.02 \mathrm{~nm}$, and those of the GaN, $a=0.32 \pm 0.02 \mathrm{~nm}$ and $c=0.52 \pm 0.03 \mathrm{~nm}$. This is a direct illustration of the SLSs, where a good lattice matching in the basal plane caused by shrinkage of the $\mathrm{Al}_{0.14} \mathrm{Ga}_{0.86} \mathrm{~N}$ lattice normal to the basal plane suppresses the generation of misfit dislocations. Dislocations, appearing as dark contours in bright-field STEM images and as bright contours in HAADF images, run either parallel or perpendicular to the $c$ direction. Another mechanism of the SLS to suppress lattice defects in the LDs has also been disclosed. (C) 2006 American Institute of Physics. [DOI: 10.1063/1.2213084]
\end{abstract}

\section{INTRODUCTION}

Up-to-date devices such as quantum-well lasers, tunneling devices, access-memory devices, and high-electronmobility transistors always comprise multilayer heterostructures, which are designed and produced with a precision as fine as nanoscale to reveal their quantum effects. Since in situ monitoring in most processing equipments is still absent, atomic-scale analysis is required to understand the real structure in the final product, including the thickness and the composition of each layer. Only then can the functional properties be improved and the quality of the products be controlled.

Recently, violet or purplish-blue light-emitting diodes (LEDs) and laser diodes (LDs) in the GaN-based multilayer system have been devised and manufactured for commercial

\footnotetext{
${ }^{\text {a)} P r e s e n t ~ a d d r e s s: ~ 1-297 ~ W a k i y a m a, ~ E n m y o j i, ~ K y o t o ~ 618-0091, ~ J a p a n ; ~ e l e c-~}$ tronic mail: shiojiri@pc4.so-net.ne.jp

${ }^{b)}$ Author to whom correspondence should be addressed; electronic mail: miran.ceh@ijs.si

${ }^{c}$ Present address: Department of Electronic Systems and Information Science, School of Biology-Oriented Science and Technology, Kinki University, Nishimitani 930, Kinokawa, Wakayama 649-6493 Japan.
}

use. The active region of these devices is made of InGaN/GaN multiple quantum wells (MQWs). ${ }^{1,2}$ The lifetime of the diodes has exceeded $10000 \mathrm{~h} ;^{3}$ this has been achieved by epitaxial lateral overgrowth of a $\mathrm{GaN}$ contact layer on a sapphire substrate and the cladding of $\mathrm{AlGaN} / \mathrm{GaN}$ strained-layer superlattices (SLSs). The epitaxial lateral growth greatly reduces the dislocation density in the GaN contact layer and consequently decreases the lattice defects in its successive layers. ${ }^{4,5}$ For optical confinement, the devices need thick AlGaN cladding layers on the GaN contact layers. The formation of the thick AlGaN layers is, however, impossible because cracks and dislocations are induced by lattice mismatch between the $\mathrm{AlGaN}$ and the $\mathrm{GaN}$. By using an $\mathrm{AlGaN} / \mathrm{GaN}$ multilayer architecture, the formation of these defects is suppressed, thus allowing the growth of thick cladding layers. ${ }^{3}$ Additionally, Mg-doped $p$-AlGaN/GaN SLSs have their hole concentration enhanced over $3 \times 10^{18} \mathrm{~cm}^{-3}$ at room temperature, which exceeds by more than ten times the value available in bulk AlGaN layers. 6,7

High-angle annular dark-field (HAADF) scanningtransmission electron microscopy (STEM) has been widely 
used to characterize defects as well as to analyze perfect crystal structures. ${ }^{8}$ HAADF-STEM imaging, mainly due to elastically scattered incoherent electrons, gives rise to strong contrast dependence on the atomic number; this is in contrast to transmission electron microscopy (TEM), where the imaging is due to elastically scattered coherent electrons. This means that HAADF-STEM allows us to determine the chemical composition of the sample being investigated. ${ }^{9,10}$

We have previously investigated the nanostructure of a GaN-based device using HAADF-STEM. ${ }^{11}$ Our results showed that even low-magnification HAADF-STEM images were able to resolve InGaN layers as thin as nanometers in the InGaN/GaN MQW active layer. ${ }^{12}$ The images also revealed that $V$ defects or inverted hexagonal pyramid defects $^{13,14}$ (IHPs) nucleate at threading dislocations and grow in the form of a thin, six-walled structure within the InGaN/GaN $\{10 \overline{1} 1\}$ layers. ${ }^{15}$ These side-walled InGaN/GaN layers might be responsible for the undesirable longwavelength emissions that were observed in addition to the main emission. ${ }^{16,17}$ We also found that the IHP even starts at In-rich dots, under adverse growth conditions. ${ }^{15} \mathrm{~A}$ highresolution HAADF-STEM image, processed by a deconvolution method, ${ }^{18,19}$ clearly defined the interface between the InGaN and GaN layers at the atomic scale. ${ }^{12}$ A HAADFSTEM image, processed by two-dimensional smoothing and deconvolution, provided both precise atom-column positions and clear contrast depending on the atomic number, thereby allowing us to map both the strain field and the In-atom distribution in successive $\mathrm{GaN}$ and InGaN layers. ${ }^{20}$ These maps indicated a local fluctuation of In atoms in the InGaN layers and then revealed that the In-rich regions, considered as quantum dots, ${ }^{21,22}$ cause lattice expansion only along the $c$ direction.

The nanostructure of the SLS cladding greatly influences the final properties of the laser. However, there have been very few structural investigations of $\mathrm{AlGaN} / \mathrm{GaN}$ SLS cladding. Saijo et $a .^{23}$ used high-resolution field-emission gun scanning electron microscopy (FEG-SEM) to resolve the $n-\mathrm{Al}_{0.14} \mathrm{Ga}_{0.86} \mathrm{~N}(3 \mathrm{~nm})$ and $n$-GaN layers $(3 \mathrm{~nm})$ in the secondary electron images. But the exact thickness of these layers could not be determined due to the insufficient point-topoint resolution of the microscope. Furthermore, it was not possible to detect the $p-\mathrm{Al}_{0.14} \mathrm{Ga}_{0.86} \mathrm{~N}(3 \mathrm{~nm})$ and $p$-GaN layers $(3 \mathrm{~nm})$. Bremser et al. ${ }^{24}$ and Pecz et al. ${ }^{25}$ used transmission electron microscopy (TEM) to observe $\mathrm{Al}_{0.2} \mathrm{Ga}_{0.8} \mathrm{~N} / \mathrm{GaN}$ and $\mathrm{Al}_{0.06} \mathrm{Ga}_{0.94} \mathrm{~N} / \mathrm{GaN}$ layers. These layers could be observed in the diffraction contours caused by small strain fields along their interfaces. However, it was not possible to identify the AlGaN and GaN layers in the images or to evaluate their exact thickness. The AlGaN and GaN layers could not be distinguished even in the high-resolution TEM (HRTEM) image shown by Bremser et al. ${ }^{24}$ Similarly, our HRTEM investigation also demonstrated that the $\mathrm{Al}_{0.14} \mathrm{Ga}_{0.86} \mathrm{~N}$ layers cannot be distinguished from the $\mathrm{GaN}$ layers in HRTEM images. Recently, however, we have reported on a determination of the thickness and the lattice distortions for an individual layer in a strained superlattice of $n$ - $\mathrm{Al}_{0.14} \mathrm{Ga}_{0.86} \mathrm{~N}$ and $n$-GaN layers using HAADF-STEM. ${ }^{26}$ In this paper we show the structural and compositional

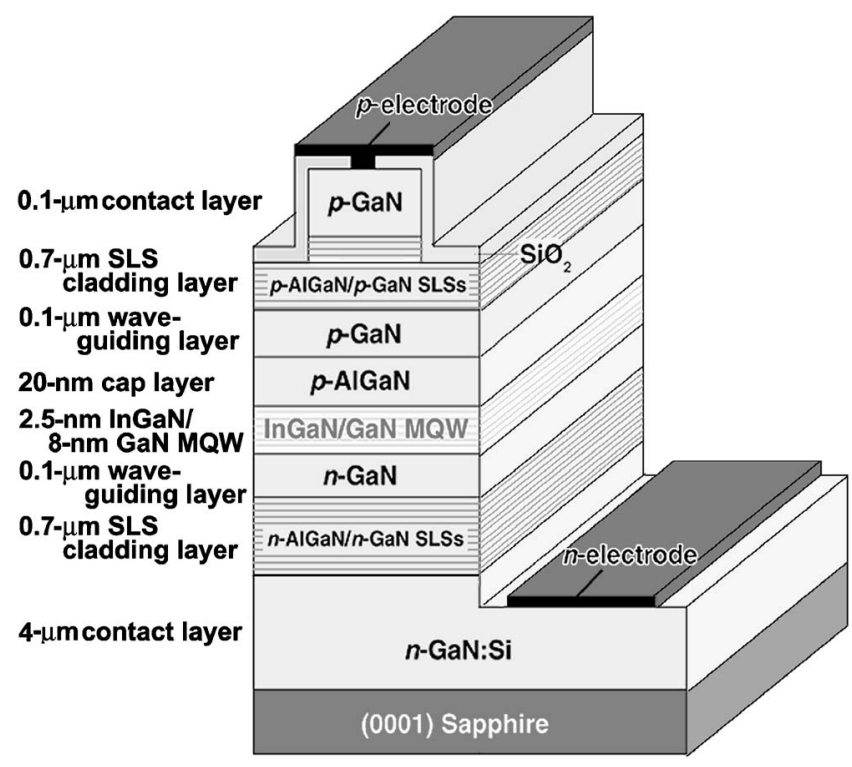

FIG. 1. The structure of a standard InGaN/GaN laser diode with marked positions of $\mathrm{Al}_{0.14} \mathrm{Ga}_{0.86} \mathrm{~N} / \mathrm{GaN}$ SLS cladding layers.

analyses of the $\mathrm{Al}_{0.14} \mathrm{Ga}_{0.86} \mathrm{~N} / \mathrm{GaN}$ SLSs using STEM, detailing the previous examination ${ }^{26}$ and elucidating the behavior of the defects to clarify the role of the SLS.

\section{EXPERIMENTAL PROCEDURE}

Metal-organic vapor-phase epitaxy (MOVPE) was used to grow 200 pairs of $n-\mathrm{Al}_{0.14} \mathrm{Ga}_{0.86} \mathrm{~N}$ and $n$-GaN layers directly onto a $2.5-\mu \mathrm{m}$-thick $n$-GaN: $\mathrm{Si}$ contact layer that was previously deposited on a (0001) sapphire substrate. The nominal thickness of each $\mathrm{Al}_{0.14} \mathrm{Ga}_{0.86} \mathrm{~N}$ or GaN layer was $3 \mathrm{~nm}$. The specimen was similar to the prototype wafer of the violet LD structure shown in Fig. 1, which had demonstrated a strong emission peak at $415.5 \mathrm{~nm}$ with two small peaks between 416 and $417 \mathrm{~nm} .{ }^{16,27}$ In the specimen used in this experiment the upper structure, including the MQW InGaN/GaN and $p$ layers, was not deposited.

The specimens with a low-index zone axis were embedded into Ti rings, ground, dimpled, and ion milled in two steps: until perforation in a Bal-Tec RES010 ion miller (4 keV, beam current of $1.2 \mathrm{~mA}$, incident angle of $10^{\circ}$, and sample oscillation) and additionally low-energy ion milled on both sides under oscillation at $300 \mathrm{eV}$ in a Gentle Mill (Technoorg Linda, model IV5). ${ }^{28}$ The additional low-energy ion milling significantly reduced the amorphous layer and artifacts caused by the sputtering. The STEM and HRTEM observations were performed in a JEM-2010F TEM/STEM, operated at $200 \mathrm{keV}$, equipped with an ultrahigh resolution polepiece $\left(C_{S}=0.48 \mathrm{~mm}\right)$. All the HAADF-STEM images were recorded with a 10-mrad semiangle of the probe and an ADF detector range from 100 to $220 \mathrm{mrad}$. The HRTEM image simulations were performed in a conventional multislice program. The HAADF-STEM image simulations were made using a scheme developed by Watanabe et al. ${ }^{29}$ It contains calculations for the Bragg scattering and thermal diffuse scattering (TDS), based on the Bethe method, using two kinds of optical potentials by Hall and Hirsch, ${ }^{30}$ and allows routine bright-field (BF)-STEM and ADF-STEM image 


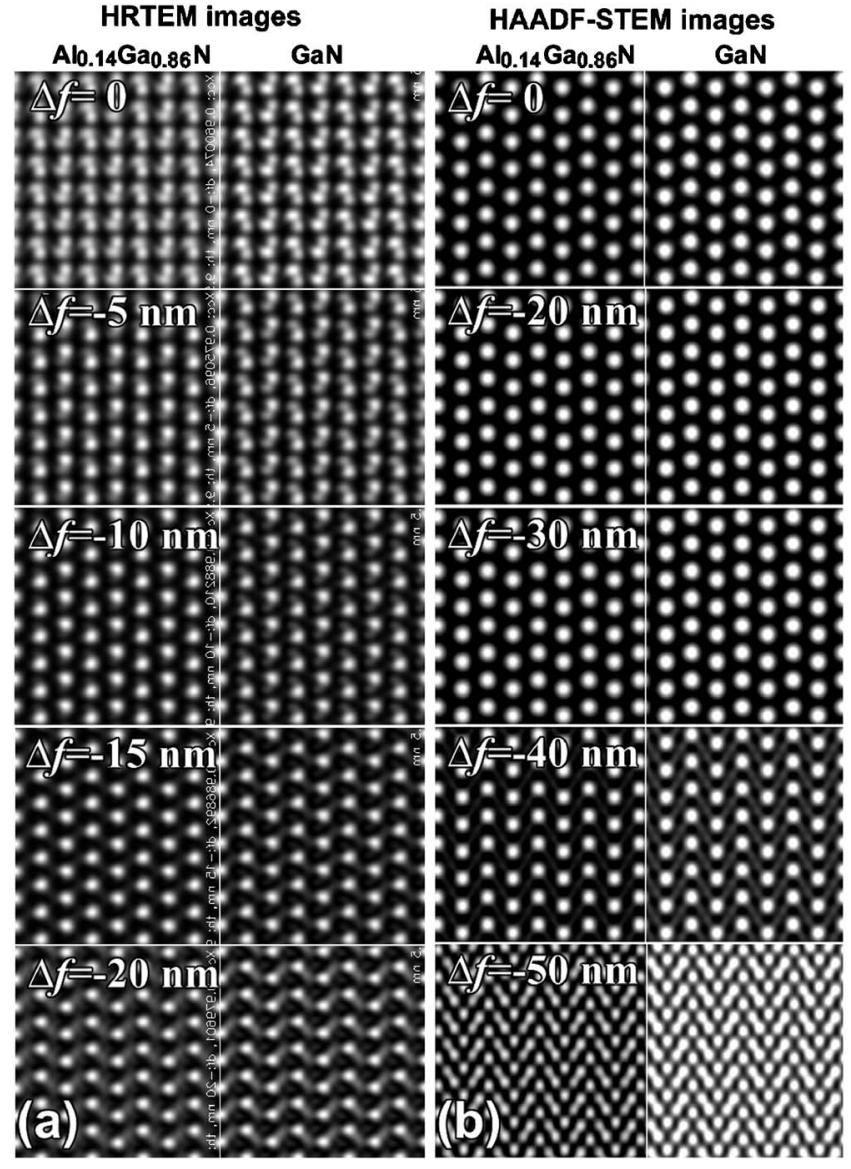

FIG. 2. Image simulations of the $[\overline{1} 2 \overline{1} 0]$-oriented $\mathrm{Al}_{0.14} \mathrm{Ga}_{0.86} \mathrm{~N}$ and $\mathrm{GaN}$ crystals, using the optical parameters of the JEOL-2010F TEM/STEM. (a) HRTEM images of the 30-nm-thick crystals calculated at different defoci values $\Delta f$. No difference can be distinguished between the $\mathrm{Al}_{0.14} \mathrm{Ga}_{0.86} \mathrm{~N}$ and the GaN. (b) Atomically resolved HAADF-STEM images of the same crystals calculated with the 100-220-mrad ADF detector range and the 10 -mrad semiangle probe focused at different $\Delta f$. The difference in the absolute intensities between the two compositions is clearly visible.

simulations. ${ }^{14,31}$ Energy-dispersive x-ray spectroscopy (EDS) nanoanalysis was carried out simultaneously in the same microscope.

\section{RESULTS AND DISCUSSION}

We performed simulations of the HRTEM and the atomically resolved HAADF-STEM images of [ $\overline{12} \overline{1} 0]$-oriented $\mathrm{Al}_{0.14} \mathrm{Ga}_{0.86} \mathrm{~N}$ and $\mathrm{GaN}$ crystals. The calculated images at different defocus values $\Delta f$ for the 30 -nm-thick crystals are illustrated in Figs. 2(a) and 2(b). The optical parameters described in Sec. II were used for the simulation. For the HRTEM the defocus of the energy spread and the convergent angle of the beam were taken to be $8 \mathrm{~nm}$ and $0.6 \mathrm{mrad}$, respectively. As can be seen in Fig. 2(a), the intensities of the HRTEM image of the corresponding $\mathrm{Al}_{0.14} \mathrm{Ga}_{0.86} \mathrm{~N}$ and $\mathrm{GaN}$ crystals are almost the same, since $\mathrm{Al}$ incorporation on the $\mathrm{Ga}$ sites in the AlGaN introduces only minimal phase shift. The cross-correlation factors between the $\mathrm{Al}_{0.14} \mathrm{Ga}_{0.86} \mathrm{~N}$ and $\mathrm{GaN}$ images are $96 \%$ for $\Delta f=0$ and $98 \%-99 \%$ for other defoci, which clearly indicate that HRTEM cannot resolve $\mathrm{Al}_{0.14} \mathrm{Ga}_{0.86} \mathrm{~N}$ and $\mathrm{GaN}$ layers. If HAADF-STEM contrast is described as the $Z$-contrast proportional to the square of the

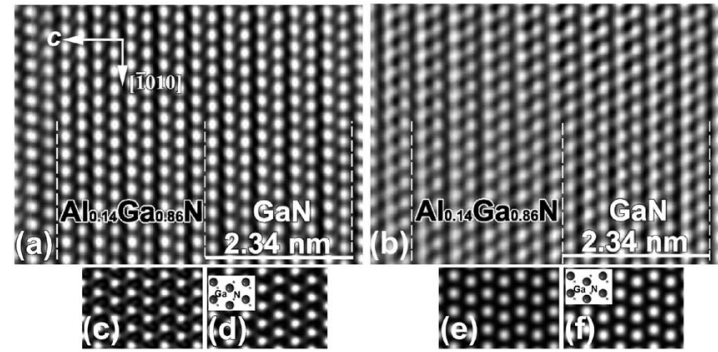

FIG. 3. [(a) and (b)] Experimental atomically resolved HRTEM and HAADF-STEM images, noise-filtering processed, of $\mathrm{Al}_{0.14} \mathrm{Ga}_{0.86} \mathrm{~N}$ and $\mathrm{GaN}$ layers in the SLS cladding, respectively. [(c) and (d)] Calculated HRTEM images of the $\mathrm{Al}_{0.14} \mathrm{Ga}_{0.86} \mathrm{~N}$ and GaN 30-nm-thick crystals at $\Delta f=-15 \mathrm{~nm}$, respectively. [(e) and (f)] Calculated HAADF-STEM images of the $\mathrm{Al}_{0.14} \mathrm{Ga}_{0.86} \mathrm{~N}$ and GaN 30-nm-thick crystals at $\Delta f=-20 \mathrm{~nm}$, respectively. The dotted lines in (a) and (b) are the interfaces between the AlGaN and $\mathrm{GaN}$, which were determined from the low-magnification HAADF-STEM image where the two layers were distinctly resolved (see Fig. 6).

atomic number, the intensity ratio of the $\mathrm{N}$ column to the $\mathrm{Ga}(\mathrm{Al})$ column in the $\mathrm{Al}_{0.14} \mathrm{Ga}_{0.86} \mathrm{~N}$ and to the Ga column in the GaN would be 5:82:100. In experimental HAADFSTEM images the Ga columns appear bright, whereas the $\mathrm{N}$ columns are dark, just above the noise level [Fig. 2(b)]. According to the low thermal diffuse scattering cross section of the $\mathrm{Al}$ atoms, the intensity of the $\mathrm{Al}_{0.14} \mathrm{Ga}_{0.86}$ columns is weaker than that of the $\mathrm{GaN}$ in the corresponding images. Figures 3(a) and 3(b) are experimental HRTEM and HAADF-STEM images of the $\mathrm{Al}_{0.14} \mathrm{Ga}_{0.86} \mathrm{~N}$ and $\mathrm{GaN}$ layers in the SLS cladding. The images were processed by a noisefiltering method, which was done on the images using a Bragg mask in the fast Fourier transform (FFT) images. The calculated images that correspond to the experimental images are also shown in Fig. 3. While it is impossible to distinguish between the $\mathrm{Al}_{0.14} \mathrm{Ga}_{0.86} \mathrm{~N}$ and $\mathrm{GaN}$ layers in the HRTEM images [Fig. 3(a)], it is possible to resolve them in the HAADF-STEM images [Fig. 3(b)], despite the very small intensity differences. Low-magnification HAADFSTEM images were also helpful in identifying the $\mathrm{Al}_{0.14} \mathrm{Ga}_{0.86} \mathrm{~N}$ and GaN layers. Finally, the HRTEM images provide the exact site information for each $\mathrm{Ga}$ or $\mathrm{AlGa}$ atom column in the layers.

Figure 4 shows a BF-STEM image that reveals the whole multiple structure as prepared for the present experiment. The BF-STEM image using the aperture with a finite radius is a result of a combination of coherent and incoherent imaging. Figures 5(a) and 5(b) show a HAADF-STEM image and a BF-STEM image of the SLS cladding layer, respectively. Two times 200 individual $\mathrm{Al}_{0.14} \mathrm{Ga}_{0.86} \mathrm{~N}$ and $\mathrm{GaN}$ layers are clearly resolved in Fig. 5(a). The $\mathrm{Al}_{0.14} \mathrm{Ga}_{0.86} \mathrm{~N}$ layers are identified as dark bands, while the GaN layers are identified as bright bands. This difference in intensity is readily confirmed by the calculation shown in Fig. 2(b). The $\mathrm{Al}_{0.14} \mathrm{Ga}_{0.86} \mathrm{~N}$ layers are numbered from the edge of the sample in Fig. 5(a). In the BF-STEM image the $\mathrm{Al}_{0.14} \mathrm{Ga}_{0.86} \mathrm{~N}$ and $\mathrm{GaN}$ layers were also visible as faint bright and dark bands as a result of the coherent phase effect and the incoherent scattering. Dislocations appear as strong dark contours as a result of diffraction contrast in the BF-STEM image, whereas they are seen in weak bright contrast in the HAADF-STEM image. 


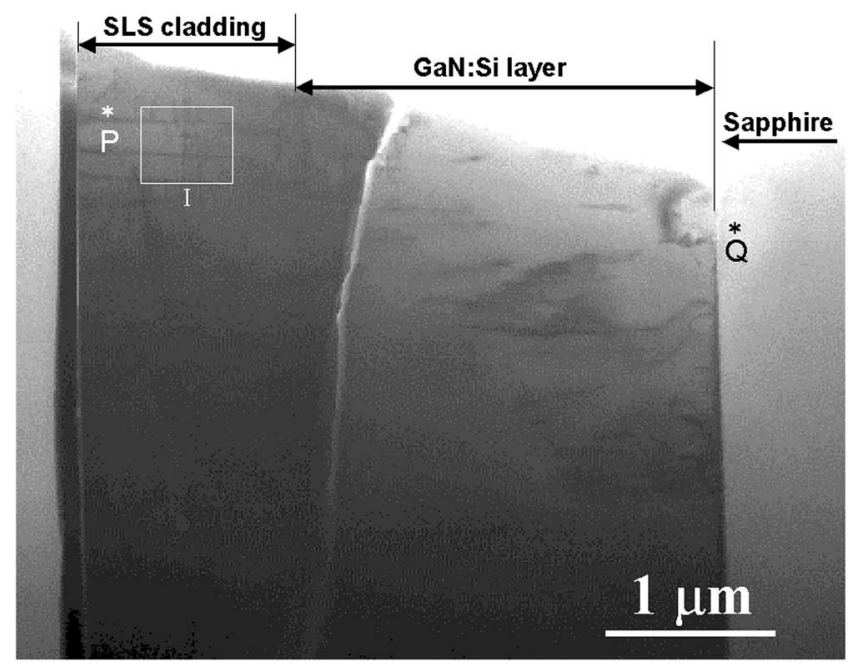

FIG. 4. Experimental bright-field STEM image of $n-\mathrm{Al}_{0.14} \mathrm{Ga}_{0.86} \mathrm{~N} / n-\mathrm{GaN}$ SLS cladding layer and $n$-GaN: Si layer prepared by metal-organic vaporphase epitaxy on the sapphire substrate. I is the area shown in Figs. 8(a) and 8(b), while $\mathbf{P}$ and $\mathbf{Q}$ are the regions for EDS nanoanalyses.

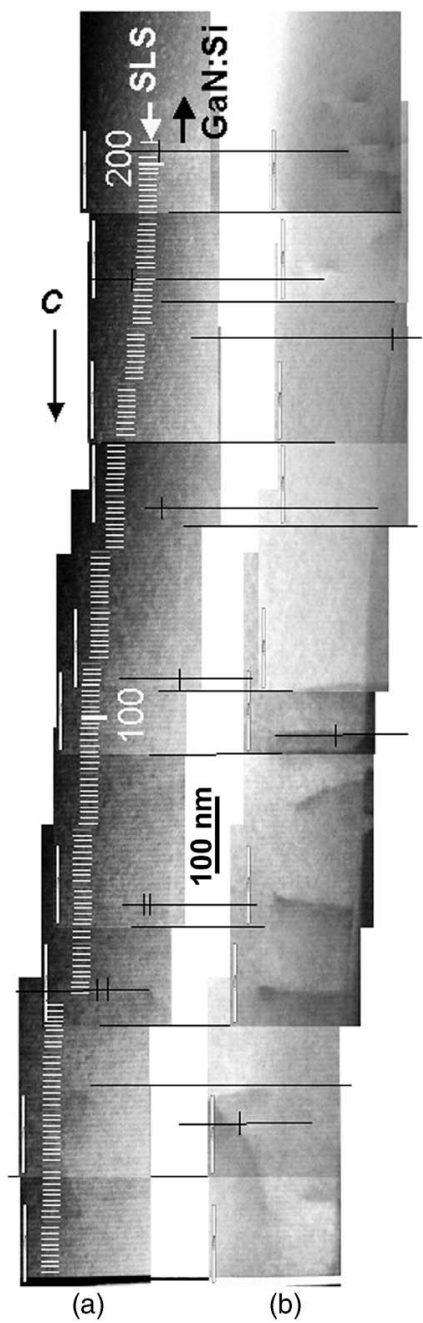

(a)

(b)

FIG. 5. (a) Experimental HAADF-STEM image of the whole SLS cladding layer. 200 pairs of $\mathrm{Al}_{0.14} \mathrm{Ga}_{0.86} \mathrm{~N}$ (dark bands) and $\mathrm{GaN}$ layers (bright bands) are clearly resolved. The $\mathrm{Al}_{0.14} \mathrm{Ga}_{0.86} \mathrm{~N}$ layers are numbered. (b) BF-STEM image of the same area. Dislocations are visible in strong diffraction contrast.
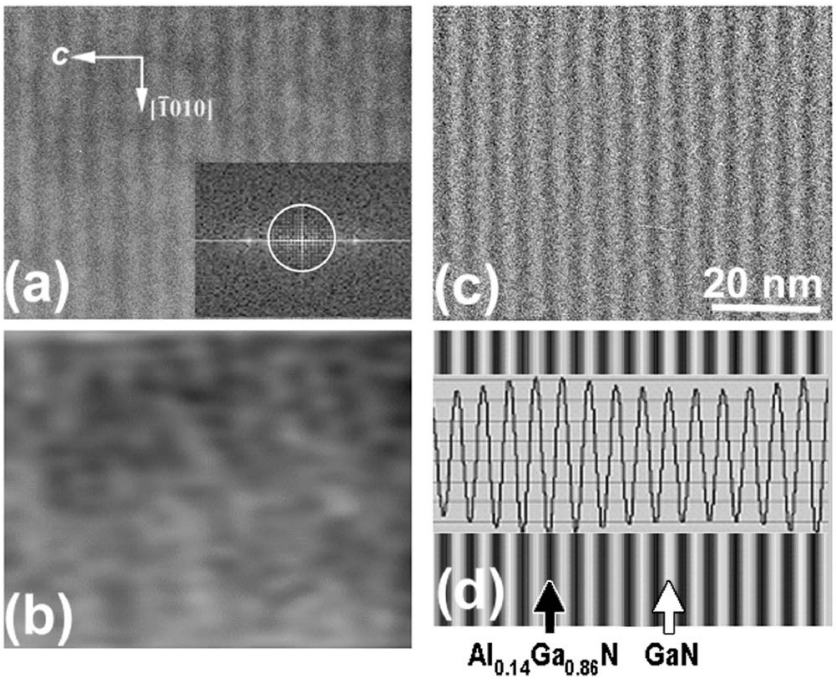

FIG. 6. (a) Experimental HAADF-STEM image of the SLS cladding. The dark bands are $\mathrm{Al}_{0.14} \mathrm{Ga}_{0.86} \mathrm{~N}$ layers, and the bright bands are $\mathrm{GaN}$ layers. Inset is the FFT image. (b) Low-frequency HAADF-STEM image reconstructed using the low-pass mask filter shown in (a). (c) Normalized HAADF-STEM image obtained by subtracting image (b) from image (a). (d) Averaged filtered normalized HAADF-STEM image and the corresponding intensity line profile. The thickness of the layers was determined according to the line profile.

In order to determine the width of the $\mathrm{Al}_{0.14} \mathrm{Ga}_{0.86} \mathrm{~N}$ and $\mathrm{GaN}$ layers in the SLS, we employed an average-filtering technique. ${ }^{26}$ First, a low-pass mask filter was applied to the FFT image of the original image of the SLS shown in Fig. 6(a). The radius of the low-pass mask, indicated in the diffractogram, was chosen so that the spots, which represent a periodic arrangement of the $\mathrm{Al}_{0.14} \mathrm{Ga}_{0.86} \mathrm{~N}$ and GaN SLS layers, were not included. The low-frequency image in Fig. 6(b) was then reconstructed by an inverse FFT of the filtered diffractogram. The subtraction of the low-pass filtered image from the original HAADF-STEM image produced the normalized HAADF-STEM image without low spatial frequencies, which is shown in Fig. 6(c). The objective of this image processing was to filter away the low-frequency noise in the experimental image and to retain all the information on the width of the $\mathrm{AlGaN}$ and $\mathrm{GaN}$ layers that is contained in the spots and close to the spots in the FFT image. The remaining streak in the FFT image was not taken into account, since its presence should not influence the width of the layers. The real-space averaged image was finally obtained by adding up all the intensity line profiles perpendicular to the $\mathrm{Al}_{0.14} \mathrm{Ga}_{0.86} \mathrm{~N}$ and $\mathrm{GaN}$ layers, which were then divided by the number of intensity line profiles. The final image and the averaged intensity profile are shown in Fig. 6(d). The thickness of the layers was estimated by measuring the width of the dark and bright bands. Since the intensity profile over the consecutive layers was sinusoidal the full-width-at-halfmaximum (FWHM) criterion was chosen to determine the width of the dark and bright layers. The average thicknesses of the $\mathrm{Al}_{0.14} \mathrm{Ga}_{0.86} \mathrm{~N}$ and $\mathrm{GaN}$ layers were thus determined to be $2.24 \pm 0.09$ and $2.34 \pm 0.15 \mathrm{~nm}$, respectively. Since the standard deviation of the thickness is quite small, the number of atomic layers in the $c$ direction of the individual $\mathrm{Al}_{0.14} \mathrm{Ga}_{0.86} \mathrm{~N}$ and $\mathrm{GaN}$ layers should be the same, i.e., 9 . 

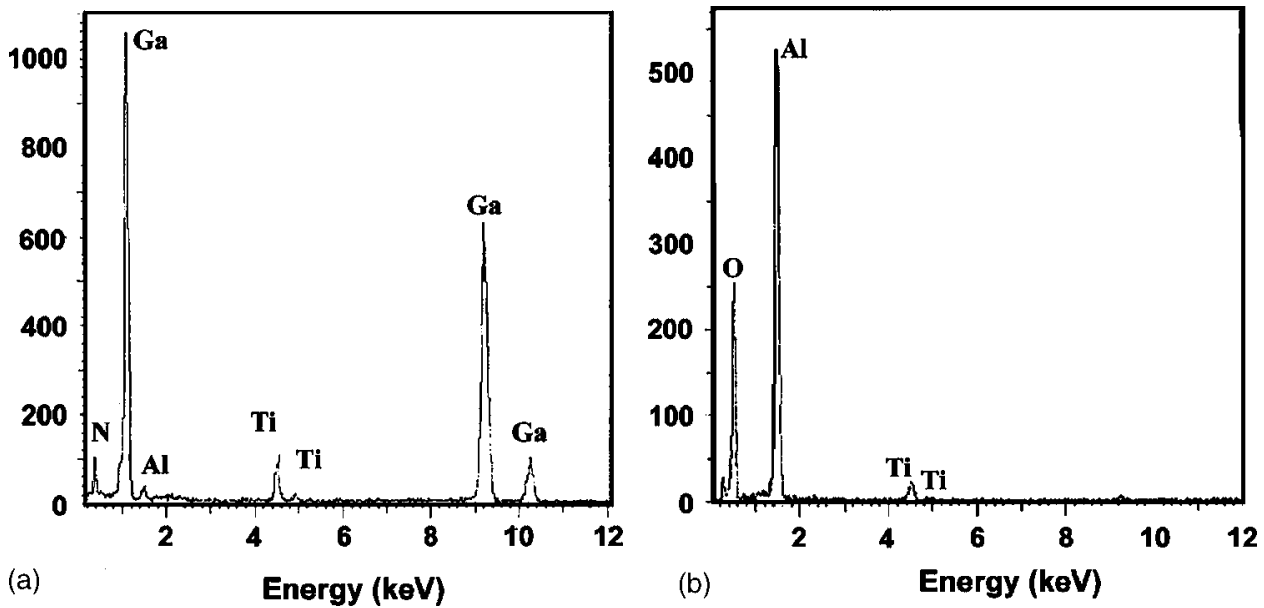

FIG. 7. [(a) and (b)] EDS spectra acquired from areas of $10 \times 10 \mathrm{~nm}^{2}$ indicated by $\mathbf{P}$ and $\mathbf{Q}$ in Fig. 4, respectively. $\mathbf{P}$ was located in the SLS layer and $\mathbf{Q}$ was located in the sapphire substrate. Ti signal originates from the sample support.
This was confirmed from the atomic-resolution HAADFSTEM images, as shown in Fig. 3(b). Accordingly, the spacing between the nearest atomic layers in the basal plane can be estimated as $0.25 \mathrm{~nm}$ (or $c=0.50 \pm 0.02 \mathrm{~nm}$ ) in the $\mathrm{Al}_{0.14} \mathrm{Ga}_{0.86} \mathrm{~N}$ and $0.26 \mathrm{~nm}(c=0.52 \pm 0.03 \mathrm{~nm})$ in the $\mathrm{GaN}$ layers. From the experimental HRTEM image shown in Fig. 3(a), we evaluated the lattice parameter $a$ to be $0.32 \pm 0.01$ and $0.32 \pm 0.02 \mathrm{~nm}$ for the $\mathrm{Al}_{0.14} \mathrm{Ga}_{0.86} \mathrm{~N}$ and $\mathrm{GaN}$, respectively. Since the lattice parameters of the pure bulk $\mathrm{GaN}$ crystal are $a=0.319 \mathrm{~nm}$ and $c=0.5189 \mathrm{~nm}$, the lattice spacing of the $\mathrm{Al}_{0.14} \mathrm{Ga}_{0.86} \mathrm{~N}$ in the SLS is almost the same in the basal plane as that of pure GaN. On the other hand, the results show that the $\mathrm{Al}_{0.14} \mathrm{Ga}_{0.86} \mathrm{~N}$ lattice shrank by $\sim 4 \%$ along the $c$ direction. It can be concluded that the distortion caused by the substitution of $\mathrm{Al}$ atoms on the Ga sites concentrated primarily along the $c$ direction and that there is no lattice misfit between the $\mathrm{Al}_{0.14} \mathrm{Ga}_{0.86} \mathrm{~N}$ and $\mathrm{GaN}$ in the basal plane. Thus, the strained lattice in the cladding layer is directly manifested through the lattice distortion in the $\mathrm{Al}_{0.14} \mathrm{Ga}_{0.86} \mathrm{~N}$ layers. The good lattice matching between the $\mathrm{Al}_{0.14} \mathrm{Ga}_{0.86} \mathrm{~N}$ and the $\mathrm{GaN}$ in the basal plane suppresses the

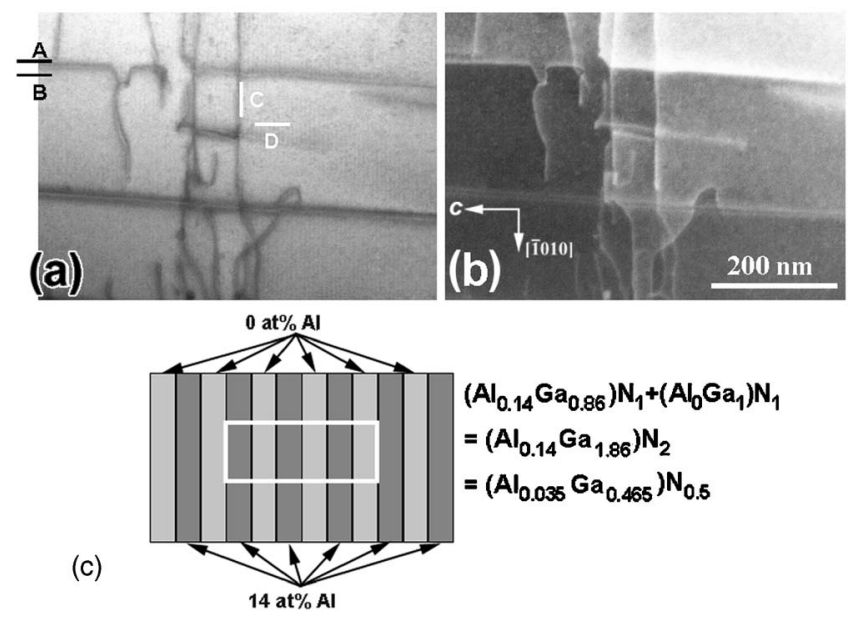

FIG. 8. (a) BF-STEM image of the area enclosed by the rectangle $\mathbf{I}$ in Fig. 4. A-D indicate the areas for EDS nanoanalysis shown in Table I. Dislocations appear as dark contours mainly caused by diffraction contrast. (b) The corresponding HAADF-STEM image. The dislocations appear as sharp bright contours. (c) The composition of pairs of $\mathrm{AlGaN} / \mathrm{GaN}$ layers in the SLS in terms of $\mathrm{Al}$ concentration. generation of misfit dislocations at the interfaces of the $\mathrm{Al}_{0.14} \mathrm{Ga}_{0.86} \mathrm{~N} / \mathrm{GaN}$ in the SLS, as well as at the interface between the $\mathrm{Al}_{0.14} \mathrm{Ga}_{0.86} \mathrm{~N}$ and $\mathrm{GaN}$ :Si layers.

The HRTEM and HAADF-STEM image simulations shown in Fig. 2 were performed for $\mathrm{Al}_{0.14} \mathrm{Ga}_{0.86} \mathrm{~N}$, relying on the nominal composition during MOVPE. For determining the chemical composition of the different regions in our sample, we used EDS nanoanalysis. The probe size that was used for the EDS analysis was $\sim 0.5 \mathrm{~nm}$. However, all the EDS spectra were acquired from frames and not from points (spot mode) in order to obtain an average composition from a larger area. The beam-broadening effect in this case did not affect the peak intensities and/or the ratios in the EDS spectrum. Figure 7(a) shows a typical EDS spectrum that was acquired from the SLS region showing the presence of $\mathrm{Ga}$, $\mathrm{Al}$, and $\mathrm{N}$. The signal for Ti originates from the specimen support. The EDS analysis was performed from an area of $10 \times 10 \mathrm{~nm}^{2}$, indicated by $\mathbf{P}$ in Fig. 4. The EDS spectrum in Fig. 7(b) was acquired from the sapphire substrate (area $\mathbf{Q}$ ) and shows only the presence of $\mathrm{Al}$ and $\mathrm{O}$. The signal for $\mathrm{Ti}$ again originates from the specimen support.

A semiquantitative EDS analysis was performed in the areas $\mathbf{A}-\mathbf{D}$ in Fig. 8(a). The results are shown in Table I. As seen in Fig. 8(c), if the analyzed area includes the same number of $\mathrm{Al}_{0.14} \mathrm{Ga}_{0.86} \mathrm{~N}$ and $\mathrm{GaN}$ layers, the average composition in the area should be $\left(\mathrm{Al}_{0.035} \mathrm{Ga}_{0.465}\right) \mathrm{N}_{0.5}$. The measured $\mathrm{Al}$ concentration in the SLS matrix areas $\mathbf{B}$ and $\mathbf{D}$ is $3.5 \pm 0.1$ at. $\%$, which confirms the composition of the $\mathrm{Al}_{0.14} \mathrm{Ga}_{0.86} \mathrm{~N}$. A somewhat higher $\mathrm{Al}$ concentration was measured in the areas $\mathbf{A}$ and $\mathbf{C}$, where the EDS spectra were acquired from dislocations parallel to the $c$ direction and in the basal plane, which suggests the precipitation of $\mathrm{Al}$ atoms around the dislocations in the SLS.

Dislocations run either parallel or perpendicular to the $c$

TABLE I. EDS analysis of the areas A-D shown in Fig. 8(a).

\begin{tabular}{crrrr}
\hline \hline \multicolumn{2}{c}{ Area $\left(\mathrm{nm}^{2}\right)$} & at. \% $\mathrm{Al}$ & at. \% Ga & at. \% N \\
\hline A & $40 \times 5$ & $3.6 \pm 0.1$ & $46.4 \pm 0.5$ & $50.0 \pm 0.5$ \\
B & $40 \times 5$ & $3.5 \pm 0.1$ & $46.5 \pm 0.5$ & $50.0 \pm 0.5$ \\
C & $1 \times 20$ & $3.7 \pm 0.1$ & $46.3 \pm 0.5$ & $50.0 \pm 0.5$ \\
D & $20 \times 1$ & $3.5 \pm 0.1$ & $46.5 \pm 0.5$ & $50.0 \pm 0.5$ \\
\hline \hline
\end{tabular}




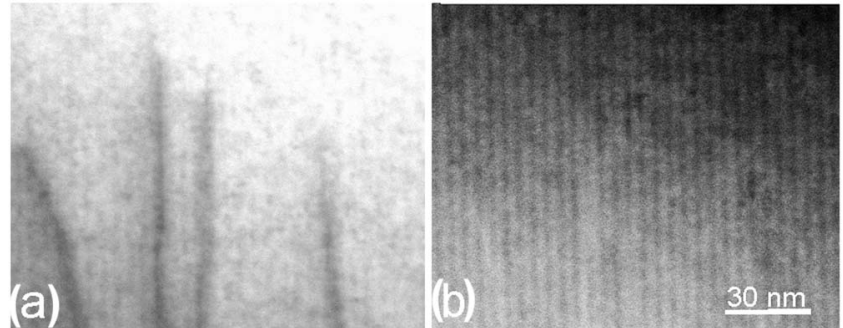

FIG. 9. [(a) and (b)] BF-STEM and HAADF-STEM images of $\mathrm{Al}_{0.14} \mathrm{Ga}_{0.86} \mathrm{~N}$ (dark bands) and GaN layers in the SLS cladding taken from the area in Figs. 8(a) and 8(b). The dislocations appear darker than the matrix due to the diffraction contrast in (a), while they appear brighter in the HAADF-STEM image (b), indicating the random static atom displacement around the dislocations.

direction, as seen in Figs. 4, 5, and 8. In the BF-STEM images the defects usually appeared as dark contours, mainly as a consequence of the diffraction contrast. Nevertheless, in the HAADF-STEM images these defects appeared brighter than the matrix, which could be the result of the static random displacement of atoms around defects. ${ }^{8}$ This static displacement of atoms enhances the diffuse scattering of the electrons and contributes to the HAADF-STEM intensity, in a similar way to thermal diffuse scattering, which is caused by the thermally agitated random displacements of atoms. While BF-STEM imaging is preferable for locating these defects, because of the strong diffraction contrast, HAADFSTEM imaging can more precisely localize them. This is made clear in Fig. 9, which shows high-resolution BF-STEM and HAADF-STEM images of the SLS.

The defects along the $c$ direction might be the threading dislocations, which are often formed in these epilayers. Some dislocations generated on the sapphire/GaN interface grew into the SLS cladding through the interface of the SLS/ GaN:Si. In spite of the defect suppression by the SLS, the dislocation density in the SLS layer is still higher than in the lower GaN:Si layer. New dislocations were formed at the interface of the SLS/GaN:Si, and they can also be formed on the $\mathrm{Al}_{0.14} \mathrm{Ga}_{0.86} \mathrm{~N} / \mathrm{GaN}$ interfaces in the SLS. When the threading dislocations in the $c$ direction reach the upper layers of the MQW InGaN/GaN, they would create $V$ defects, which are very unfavorable for laser emission. ${ }^{15-17}$ Dislocations in the basal planes seem to be converted from the threading dislocations. These dislocations, seen in Figs. 8(a) and $8(\mathrm{~b})$, could not reach the upper MQW. As a result the number of defects in the MQW would be reduced. This clearly shows the important role of the SLS, which suppresses the defect propagation that results in the overall reduction of structural defects in the active MQW layer.

\section{CONCLUSION}

We investigated the $n-\mathrm{Al}_{0.14} \mathrm{Ga}_{0.86} \mathrm{~N}$ and $n$-GaN layers in SLS cladding using a scanning-transmission electron microscope.

(1) The $n-\mathrm{Al}_{0.14} \mathrm{Ga}_{0.86} \mathrm{~N}$ and $n$-GaN layers were distinguished as dark and bright bands in the HAADF-STEM images. With the aid of image processing, the average thicknesses of the $n-\mathrm{Al}_{0.14} \mathrm{Ga}_{0.86} \mathrm{~N}$ and $\mathrm{GaN}$ layers in the
SLS were determined to be $2.24 \pm 0.09$ and $2.34 \pm 0.15 \mathrm{~nm}$, respectively, which correspond to nine atom layers in the $c$ direction. The $\mathrm{AlGaN}$ lattice shrunk by $\sim 4 \%$ along the $c$ direction, while no change was measured in the basal plane, as compared with the GaN lattice. This is a direct illustration of the strained lattice in the cladding layer. Namely, good lattice matching in the basal plane between the AlGaN and the GaN suppresses the generation of misfit dislocations on the $\mathrm{Al}_{0.14} \mathrm{Ga}_{0.86} \mathrm{~N} / \mathrm{GaN}$ interfaces in the SLS as well as at the interface between the $\mathrm{Al}_{0.14} \mathrm{Ga}_{0.86} \mathrm{~N}$ and $\mathrm{GaN}$ :Si layers.

(2) Semiquantitative EDS nanoanalysis confirmed the chemical composition of the $\mathrm{Al}_{0.14} \mathrm{Ga}_{0.86} \mathrm{~N}$. It also suggested that the threading dislocations and dislocations in the basal plane in the SLS layers are rich in Al.

(3) Dislocations run either parallel or perpendicular to the $c$ axis. Whereas they appear as dark contours due to diffraction contrast in BF-STEM images, they appear as bright contours in HAADF-STEM images as a result of a random static atom displacement around the dislocations. It was found that the threading dislocations reverted from running along the $c$ direction to running in the basal plane. The converted dislocations would not reach the upper MQW layer. This clearly shows the important role of the SLS in suppressing the defect propagation, which results in the overall reduction in the number of structural defects in the active MQW layer.

Since HAADF-STEM imaging contrast depends directly on the composition of the layers, being able to distinguish between the $p$-AlGaN and $p$-GaN layers, which a FEG-SEM failed to do, ${ }^{25}$ should be possible using HAADF-STEM. The control of thickness and the elimination of defects in the SLS cladding are very important for the fabrication of these laser devices. Therefore, HAAD-STEM should become a key analytical tool for the characterization of nanostructures such as SLS.

\section{ACKNOWLEDGMENTS}

We thank M. Gec, Jožef Stefan Institute, Slovenia for the specimen preparation for the STEM observations and also T. C. Wang and C. E. Tsai for assistance with the MOCVD growth, which was financially supported by Project No. A341XS3N10 by the Ministry of Economic Affairs of Taiwan, R.O.C. Thanks are due to Dr. M. Kawasaki, JEOL US, and Dr. Y. Yabuuchi, Matsushita Technoresearch, for helpful discussions.

${ }^{1}$ I. Akasaki, H. Amano, S. Sota, H. Sakai, T. Tanaka, and M. Koike, Electron. Lett. 32, 1105 (1996).

${ }^{2}$ S. Nakamura, M. Senoh, S. Nagahara, N. Iwasa, S. Saito, T. Matsushita, Y. Sugimoto, and H. Kiyoku, Appl. Phys. Lett. 69, 4056 (1996).

${ }^{3}$ S. Nakamura et al., Appl. Phys. Lett. 72, 211 (1998).

${ }^{4}$ A. Usui, H. Sunakawa, A. Sakai, and A. Yamaguchi, Jpn. J. Appl. Phys., Part 2 36, L899 (1997).

${ }^{5}$ O. H. Nam, M. D. Bremser, T. Zheleva, and R. Davis, Appl. Phys. Lett. 71, 2638 (1997).

${ }^{6}$ K. Kumakura, T. Makimoto, and N. Kobayashi, Jpn. J. Appl. Phys., Part 1 39, 2428 (2000).

${ }^{7}$ P. Kozodoy, M. Hansen, S. P. DenBaars, U. K. Mishra, and J. Kauffman, 
Appl. Phys. Lett. 74, 3681 (1999).

${ }^{8}$ S. J. Pennycook and P. D. Nellist, in Impact of Electron and Scanning Probe Microscopy on Materials Research, edited by D. G. Rickerby, G. Valdre, and U. Valdre (Kluwer Academic, Dordrecht, 1999), pp. 161-207.

${ }^{9}$ M. Kawasaki, T. Yamazaki, S. Sato, K. Watanabe, and M. Shiojiri, Philos. Mag. A 81, 245 (2001).

${ }^{10}$ T. Yamazaki, K. Watanabe, Y. Kikuchi, M. Kawasaki, I. Hashimoto, and M. Shiojiri, Phys. Rev. B 61, 13833 (2000).

${ }^{11}$ M. Shiojiri, Electron Technol. 36, 1 (2004).

${ }^{12}$ K. Watanabe, J. R. Yang, N. Nakanishi, K. Inoke, and M. Shiojiri, Appl. Phys. Lett. 80, 761 (2002).

${ }^{13}$ Z. Liliental-Weber, Y. Chen, S. Ruvimov, and J. Washburn, Phys. Rev Lett. 79, 2835 (1997).

${ }^{14}$ X. H. Wu, C. R. Elsass, A. Abare, M. Mack, S. Keller, P. M. Petroff, S. P DenBaars, and J. S. Speck, Appl. Phys. Lett. 72, 692 (1998).

${ }^{15}$ K. Watanabe et al., Appl. Phys. Lett. 82, 718 (2003).

${ }^{16}$ R. C. Tu, W. H. Kuo, T. C. Wang, C. J. Tun, F. C. Hwang, J. Y. Chi, and J. T. Hsu, Proceeding of the Fourth International Symposium on Blue Laser and Light Emitting Diodes, Cordoba, Spain, 2002, p. 1.

${ }^{17}$ H. Saijo, J. T. Hsu, R. C. Tu, M. Yamada, M. Nakagawa, J. R. Yang, and M. Shiojiri, Appl. Phys. Lett. 84, 2271 (2004).

${ }^{18} \mathrm{~K}$. Watanabe, Y. Kotaka, N. Nakanishi, T. Yamazaki, I. Hashimoto, and M. Shiojiri, Ultramicroscopy 92, 191 (2002).

${ }^{19}$ T. Yamazaki, N. Nakanishi, A. Rečnik, M. Kawasaki, K. Watanabe, M.
Ceh, and M. Shiojiri, Ultramicroscopy 98, 305 (2004).

${ }^{20} \mathrm{~K}$. Watanabe et al., Appl. Phys. Lett. 82, 715 (2003).

${ }^{21}$ S. Nakamura, T. Mukai, M. Senoh, S. Nagahama, and N. Iwasa, J. Appl. Phys. 74, 3911 (1993).

${ }^{22}$ T. Takeuchi, H. Takeuchi, S. Sato, H. Sakai, and H. Amano, Jpn. J. Appl. Phys., Part 2 36, L177 (1997).

${ }^{23}$ H. Saijo, M. Nakagawa, M. Yamada, J. T. Hsu, R. C. Tu, J. R. Yang, and M. Shiojiri, Jpn. J. Appl. Phys., Part 1 43, 968 (2004).

${ }^{24}$ M. D. Bremser, W. G. Perry, T. Zheleva, N. V. Edwards, Q. H. Nam, N. Parikh, D. E. Aspnes, and R. F. Davis, MRS Internet J. Nitride Semicond. Res. 1, 8 (1996)

${ }^{25}$ B. Pecz, Zs. Makkai, M. A. di Forte-Poisson, F. Huet, and R. E. DuninBorkowski, Appl. Phys. Lett. 78, 1529 (2001).

${ }^{26}$ M. Shiojiri, M. Čeh, S. Šturm, C. C. Chuo, J. T. Hsu, J. R. Yang, and H. Saijo, Appl. Phys. Lett. 87, 031914 (2005).

${ }^{27}$ R. C. Tu et al., IEEE Electron Device Lett. 24, 206 (2003).

${ }^{28}$ M. Gec, M. Čeh, and M. Shiojiri, Proceedings of Seventh Multinational Congress on Mocroscopy, Portoroz, Slovenia, 2005, p. 385.

${ }^{29}$ K. Watanabe, T. Yamazaki, I. Hashimoto, and M. Shiojiri, Phys. Rev. B 64, 115432 (2001).

${ }^{30}$ C. R. Hall and P. B. Hirsch, Proc. R. Soc. London, Ser. A 286, 158 (1965).

${ }^{31} \mathrm{M}$. Shiojiri and T. Yamazaki, JEOL News, Electron Opt. Instrum. 38, 54 (2003). 